\title{
Retraction Note to: Synthesis, Structural and Magnetic Properties of Polypyrrole Coated $\mathrm{Ni}_{0.2} \mathrm{Ca}_{0.8} \mathrm{Fe}_{2} \mathrm{O}_{4}$ Nanocomposite
}

\author{
Arun S. Prasad • S. N. Dolia • M. S. Dhawan •
}

S. Kumar • V. R. Reddy

Published online: 22 January 2015

(C) Springer Science+Business Media New York 2015

\section{Retraction to: J Supercond Nov Magn (2012) 25:1921-1927 DOI 10.1007/s10948-012-1513-5}

Because of scientific errors, Prasad, A.S., Dolia, S.N., Dhawan, M.S., Kumar, S., Reddy, V.R.: Synthesis, Structural and Magnetic Properties of Polypyrrole Coated $\mathrm{Ni}_{0.2} \mathrm{Ca}_{0.8} \mathrm{Fe}_{2} \mathrm{O}_{4}$ Nanocomposite. Journal of Superconductivity and Novel Magnetism 25, 1921-1927 (2012). doi: 10.1007/s10948-012-1513-5 has been retracted at the request of the authors. The paper was previously corrected with an Erratum: Prasad, A.S., Dolia, S.N., Dhawan, M.S., Kumar, S., Reddy, V.R.: Erratum to: Synthesis, Structural and Magnetic Properties of Polypyrrole Coated $\mathrm{Ni}_{0.2} \mathrm{Ca}_{0.8} \mathrm{Fe}_{2} \mathrm{O}_{4}$ Nanocomposite. Journal of Superconductivity and Novel Magnetism 26, 2985 (2013). doi: 10.1007/ s10948-013-2314-1.

The online version of the original article can be found at http://dx.doi.org/10.1007/s10948-012-1513-5.

\section{A. S. Prasad $(\bowtie)$ \\ Department of Physics, Arulmigu Meenakshi Amman College of Engineering, Vadamavandal \\ (Near Kanchipuram), Tamil Nadu 604 410, India \\ e-mail: asp.physics@gmail.com}

S. N. Dolia · M. S. Dhawan

Department of Physics, University of Rajasthan,

Jaipur, Rajasthan 302 004, India

\section{S. Kumar}

Department of Physics, M. L. Sukhadia University,

Udaipur, Rajasthan 313002 India

V. R. Reddy

UGC-DAE CSR, Khandwa Road, Indore,

Madhya Pradesh 452 017, India 